\title{
Effects of Denervation and Deafferentation on Mass and Enzyme Activity in Rat Skeletal Muscles
}

\author{
Yoshinobu OHIRA \\ Department of Physiology and Biomechanics, National Institute of Fitness and Sports, \\ Kanoya, Kagoshima, 891-23 Japan
}

\begin{abstract}
Effects of denervation and deafferentation on mass and enzyme activity of soleus and plantaris muscles were studied when the synergistic gastrocnemius was either intact or tenotomized in adult male Wistar rats. Denervation of the sciatic nerve at L4 and L5 induced a severe atrophy (approximately $50 \%$ ) in both soleus and plantaris within 2 weeks. Deafferentation at L4 and L5 also caused a decrease in muscle weight for soleus and plantaris (approximately 11 and 24\%, respectively). No compensatory response to the tenotomy was induced either for muscle weight or enzyme activity in both denervated and deafferentated muscles. It is suggested that the efferent information(s) through the nerve fibers has an important effect of the regulation of both muscle mass and enzyme activity. Its effect on the activities was greater in mitochondrial than cytoplasmic enzymes. The data also suggest that the afferent information(s) plays a significant role for the regulation of muscle mass, including an induction of compensatory hypertrophy, but not for enzyme activity.
\end{abstract}

Key words: denervation, deafferentation, compensatory hypertrophy, skeletal muscle enzymes.

Muscle hypertrophy occurs following stretching (FrANKENY et al., 1983; AsHMORE et al., 1984) or increased load by elimination of synergistic muscle (Crawford, 1961; Goldberg, 1967; Hamosh et al., 1967; GoldspinK et al., 1983; SCHIAFFINO and HANZLIKOVA, 1970; JAWEED et al., 1987). On the other hand, disuse caused by denervation (NEMETH et al., 1980), joint immobilization (BоOTH, 1977, 1982; HERBISON et al., 1978), space flight (ILYINA-KAKUEVA et al., 1976; LEONARD et al., 1983), or body suspension (MusACCHIA et al., 1980; FLYNN and MAX, 1985; OHIRA et al., 1987) induces an atrophy. It is also known that use and disuse change the metabolic characteristics of muscles (Holloszy, 1967; CoYle et al., 1984; OHIRA et al., 1987). However, it is still unclear what is the key factor(s) which induces such

Received for publication October 3, 1988 
changes in skeletal muscles. The major limitation is that it is difficult to examine the effect of a single factor separated from others in vivo. This problem might be solved by using a tissue culture system. It was reported that stretching of cultured myotubes and fibroblasts without nerve innervation caused hypertrophy (VANDENBURGH and KaUfMan, 1979, 1980). However, atrophy was induced in our study when denervated mature muscles in adult frogs were stretched in an organ culture system, suggesting an important regulation by neural factor(s) (OHIRA et $a l$. in press). Therefore, the current study was carried out to investigate what kind of role is played by the neural information in the regulation of mass and enzymatic characteristics in mature muscle with or without tenotomy of synergistic muscle.

\section{MATERIALS AND METHODS}

Adult male Wistar rats, with mean \pm S.E.M. body weight of $379 \pm 7 \mathrm{~g}$, were utilized in the study. They were housed individually in stainless steel cages. Solid rat food and water were supplied ad libitum throughout the experiment. Light-dark cycle in the animal room was controlled every $12 \mathrm{~h}$ and the temperature and humidity were maintained at approximately $23^{\circ} \mathrm{C}$ and $55 \%$, respectively. The experiment was performed following the institution's guideline for animal care.

The animals were anesthetized by i.p. injection of sodium pentobarbital ( $5 \mathrm{mg} / 100 \mathrm{~g}$ of body weight) for surgical operation which was performed on the left sciatic nerve and the distal tendon of the gastrocnemius muscle. The right side served as the contralateral control. For deafferentation and denervation, the left side of the spine was carefully opened at the dorsal lumbar regions so as to avoid bleeding and damage to the nerve fibers (JAWEED et al., 1987). After exposing the afferent and efferent fibers at both L 4 and L5, approximately $5 \mathrm{~mm}$ of afferent fibers including the ganglion were sectioned for deafferentation (DR) to avoid regeneration of nerve fibers. Both bundles of fibers running toward the dorsal and ventral roots were sectioned at the same level for denervation (SN). In one group, these fibers were cut at only L4 (SN(L4)). Following such operations, a portion of tygon tubing (inner diameter, $5 \mathrm{~mm}$; length, $1 \mathrm{~cm}$ approximately), which was cut into two parts longitudinally, was placed above the nerves in order to keep the exposed fibers away from the surrounding tissues and then skin was sutured. Completeness of the neurectomy was examined by palpating the response of muscle to electrical stimulation $(100 \mu$ s duration of square wave, $1 \mathrm{~Hz})$ through either the distal or proximal end of the nerve fibers. Any rats which had injury in nerve fibers and/or excessive bleeding were excluded from the study. Since muscles at the dorsal regions were cut, effects of such surgery on the characteristics of hindlimb muscles might be severe. Therefore, in one group the spine was opened and the nerve fibers were exposed in the same way but not cut; these were termed the sham-operated control (SC).

Each group (DR, $\mathrm{SN}$, and $\mathrm{SN}(\mathrm{L} 4)$ ) was further subdivided into two groups of which one group was tenotomized at the distal end of the gastrocnemius 
muscle $(+\mathrm{G})$. One group of normal control received no operation $(\mathrm{NC})$ but another was tenotomized without spinal operation $(\mathrm{G})$. Overall, the total number of groups was 9: NC, SC, G, DR, DR + G, SN, SN + G, SN(L4), and SN(L4) + G. Each group consisted of six to eight rats.

Muscle sampling was performed following body weight measurement 2 weeks later. After re-testing the nerve-evoked contraction in response to electrical stimulation, soleus and plantaris muscles were dissected out from both hindlimbs under anesthesia with i.p. injection of sodium pentobarbital $(5 \mathrm{mg} / 100 \mathrm{~g}$ body weight). Wet weight of these muscles was measured immediately. Muscles were homogenized with polytron in $175 \mathrm{~mm}$ potassium chloride, $10 \mathrm{~mm}$ Trishydrochloride, and $2 \mathrm{~mm}$ ethylenediaminetetraacetic acid ( $\mathrm{pH}$ 7.2). Spectrophotometric assays were performed for citrate synthase (SRERE, 1969), $\beta$ hydroxyacyl CoA dehydrogenase (BASs et al., 1969), lactate dehydrogenase (PESCE et al., 1964), and protein (LowRY et al., 1951).

The statistical significance of the data in the control side was examined by analysis of variance between nine groups. Since significant difference was not observed, the effect of each treatment was compared between the experimental and the contralateral control sides in the same animal by using paired $t$-test.

\section{RESULTS}

Effects of surgical treatment in one limb on the contralateral control limb were not seen when the enzyme activities and muscle weight were compared between the 9 groups. Therefore, all of the comparisons were performed between the experimental and contralateral control muscles.

\section{Muscle weight}

Effects of various surgical treatments on the wet weight of the plantaris muscle are shown in Fig. 1. Sham-operation itself decreased the weight (approximately $9 \%$, $p<0.001$ ) in the experimental limb relative to the contralateral control. The tenotomy of the synergistic gastrocnemius muscle caused a compensatory hypertrophy in the plantaris muscle with normal innervation $(11 \%, p<0.05)$. However, no compensatory effect was observed in denervated and deafferentated muscles. The mean \pm S.E.M. weight relative to body weight in plantaris denervated at both L4 and L5 was $0.045 \pm 0.003 \%$ and significantly less than that $(0.102 \pm 0.003 \%)$ in the contralateral control side $(p<0.001)$. No significant atrophy in plantaris was caused by denervation at only L4. Atrophy was also induced by deafferentation at both L4 and L5 $(p<0.05)$. But the degree of the atrophy $(33 \%$; net atrophy was $24 \%)$ was less than that caused by denervation.

In soleus muscle, atrophy following the sham-operation and compensatory hypertrophy in response to the tenotomy of the gastrocnemius were not statistically significant (Fig. 2). The denervation of the sciatic nerve at L4 and L5 caused about $59 \%$ of atrophy $(p<0.001$; net atrophy was approximately $48 \%$ ). Decrease in wet 


\section{Plantaris Wet Weight}

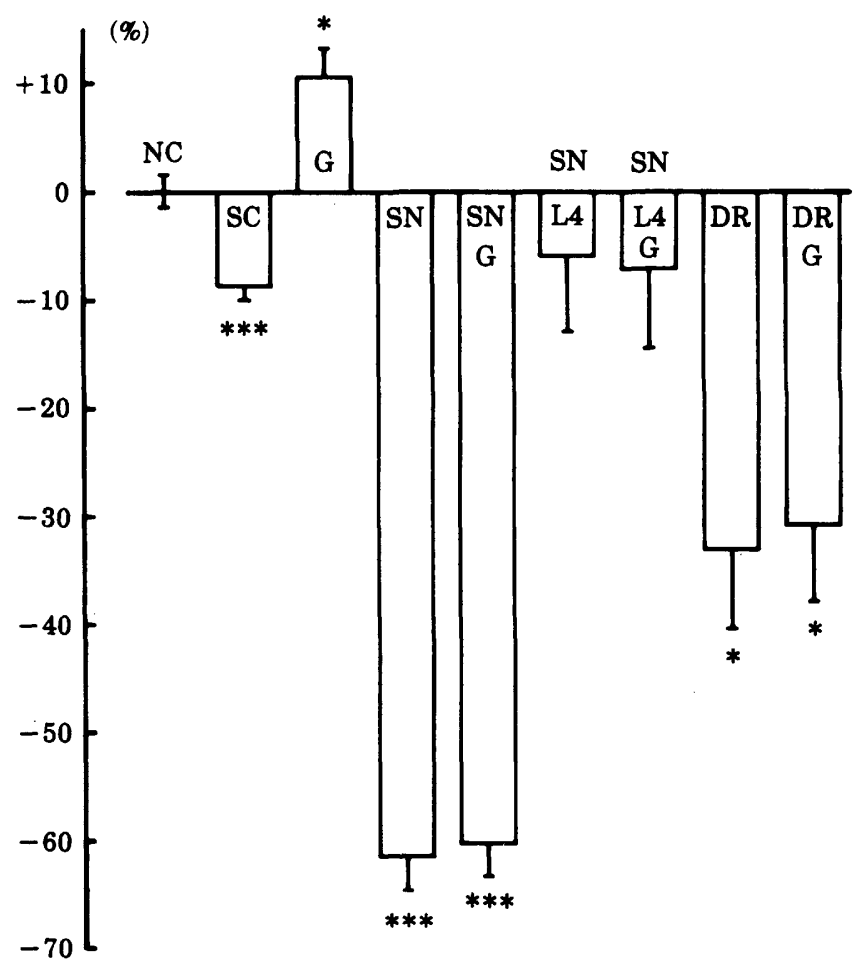

Fig. 1. Percent changes in plantaris wet weight relative to the contralateral control. Mean \pm S.E.M. ${ }^{*} p<0.05$ and ${ }^{* * *} p<0.001$ by paired $t$-test. NC, normal control; $\mathrm{SC}$, sham-operated control; G, tenotomy of gastrocnemius; $\mathrm{SN}$, denervation of sciatic nerve at L4 and L5; SN (L4), denervation of sciatic nerve at L4; DR, deafferentation of sciatic nerve at L4 and L5.

weight by the denervation at L4 only was approximately $30 \%(19 \%$ net atrophy) relative to the contralateral control $(p<0.01)$. And about $22 \%(11 \%$ in net $)$ atrophy was observed after the deafferentation at L4 and L5 $(p<0.05)$. Compensatory retardation of atrophy following the tenotomy of synergistic muscle was not seen in any of the neurectomized groups.

Total protein in muscle (not shown in either the figures or table) had the same tendency as the wet weight shown in Figs. 1 and 2, suggesting that the changes in the muscle weight were caused by alteration of protein content. The concentration of protein $(\mathrm{mg} / \mathrm{g}$ wet muscle weight) decreased in the experimental musclesapproximately $10 \%$ in the denervated plantaris and $28 \%$ in the denervated soleus both with and without tenotomy of gastrocnemius, and $17 \%$ in the soleus denervated at only L4. 


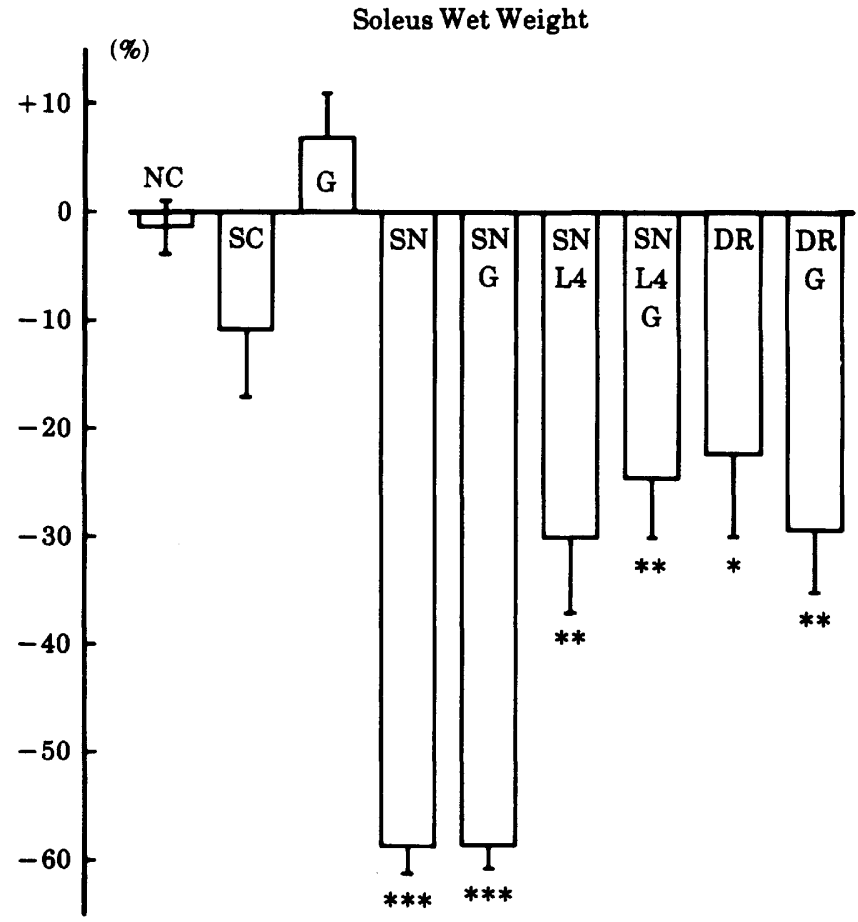

Fig. 2. Percent changes in soleus wet weight relative to the contralateral control. Mean \pm S.E.M. ${ }^{*} p<0.05,{ }^{* *} p<0.01$, and ${ }^{* * *} p<0.001$ by paired $t$-test. See Fig. 1 for the abbreviation of each group.

\section{Enzyme activity}

No changes in the activities of citrate synthase, $\beta$-hydroxyacyl CoA dehydrogenase, and lactate dehydrogenase were induced by sham-operation (Table 1). Statistical significance was found only in the soleus citrate synthase $(p<0.05)$, although all of the mean enzyme activities in both soleus and plantaris tended to be less than the contralateral control when the synergistic gastrocnemius muscle was tenotomized. Denervation of the sciatic nerve at both L4 and L5 decreased the activities of the three enzymes in both muscles. For example, the mean \pm S.E.M. activities of citrate synthase, $\beta$-hydroxyacyl $\operatorname{CoA}$ dehydrogenase, and lactate dehydrogenase in the denervated soleus vs. the contralateral control were $19.2 \pm 1.0$ vs. $33.9 \pm 2.8(p<0.001), 9.9 \pm 0.7$ vs. $25.3 \pm 2.0 \quad(p<0.001)$, and $317 \pm 19$ vs. $420 \pm 13(p<0.05) \mu \mathrm{mol} /(\mathrm{g} \cdot \mathrm{min})$, respectively. The percent decrease tended to be greater in the mitochondrial than the cytoplasmic enzymes. In plantaris, only citrate synthase decreased the activity significantly $(p<0.05)$ by combination of denervation and tenotomy, although the other two enzymes also tended to decrease $(p>0.05)$. The decrease was statistically significant in all enzymes of soleus.

Enzymatic responses to denervation at L4 showed a similar pattern of changes 
Table 1. Percent changes in enzyme activities

\begin{tabular}{lrrr}
\hline & \multicolumn{3}{c}{ Plantaris } \\
\cline { 2 - 4 } & \multicolumn{1}{c}{ CS } & \multicolumn{1}{c}{ HOAD } & \multicolumn{1}{c}{ LDH } \\
\hline NC & $+3.5 \pm 5.0$ & $+1.5 \pm 2.0$ & $-0.7 \pm 1.8$ \\
SC & $+2.5 \pm 7.3$ & $-9.1 \pm 12.6$ & $-3.8 \pm 5.9$ \\
G & $-3.3 \pm 5.7$ & $-21.7 \pm 9.0$ & $-2.7 \pm 5.7$ \\
SN & $-39.0^{* *} \pm 5.8$ & $-41.8^{* *} \pm 6.9$ & $-27.0^{* *} \pm 5.5$ \\
SN +G & $-35.8^{*} \pm 12.4$ & $-19.1 \pm 10.4$ & $-25.6 \pm 11.6$ \\
SL(L4) & $-1.7 \pm 5.5$ & $-1.5 \pm 12.6$ & $+6.7 \pm 7.9$ \\
SN(L4)+G & $-2.7 \pm 10.3$ & $-1.3 \pm 6.9$ & $+1.5 \pm 7.5$ \\
DR & $-13.5 \pm 12.0$ & $-20.3 \pm 11.8$ & $-16.1 \pm 11.3$ \\
DR + G & $-12.2 \pm 8.8$ & $-22.2 \pm 13.1$ & $-19.7 \pm 9.4$ \\
\hline
\end{tabular}

Mean \pm S.E.M. ${ }^{*} p<0.05,{ }^{* *} p<0.01$, and ${ }^{* * *} p<0.001$ by paired $t$-test. CS, citrate Fig. 1 for the abbreviation of each group.

as in the muscle weight. Both with and without synergistic tenotomy, only soleus $\beta$ hydroxyacyl CoA dehydrogenase activity decreased significantly $(p<0.05)$. No significant effects, except a decreased lactate dehydrogenase activity in soleus $(p<0.05)$, were caused by the deafferentation either with or without tenotomy of gastrocnemius.

\section{DISCUSSION}

Significant atrophy of muscles was induced following denervation. DAvis and HEINICKE (1984) reported that trophic action of mammalian nerve extract prevented denervation atrophy of rat muscles. The results of the study performed by MARKELONIS and $\mathrm{OH}(1978)$ indicated that the trophic effects of nerve may be due to the transport of a biologically active protein from nerve to muscle. Their study $(\mathrm{OH}$ et al., 1980) also suggested that the trophic effect of neural protein persisted when the nerve was transected, even though the effect of the neural protein was examined in cultured myogenic cell. Our previous study (OHIRA et al., 1987) showed that unloading of rat hindlimbs, with intact nerve supply, by suspension caused an atrophy in soleus $(52 \%)$, plantaris $(54 \%)$, and gastrocnemius muscles $(55 \%)$ when the absolute wet weight was compared with normal control. The loss of the weight relative to the body weight was 28,31 , and $32 \%$ in these muscles, respectively. These results may suggest that the greater atrophy in the muscles denervated in both afferent and efferent fibers may be caused by the complete loss of the voluntary and reflex-induced contractile activities in addition to the neural impulse conduction. The degree of atrophy was less but still significant when the afferent fibers were sectioned leaving the efferent fibers intact. This result may be caused by the use of muscles maintained in some degree even after deafferentation. These findings from 
relative to the contralateral control.

\begin{tabular}{rrr}
\hline \multicolumn{3}{c}{ Soleus } \\
\hline \multicolumn{1}{c}{ CS } & \multicolumn{1}{c}{ HOAD } & \multicolumn{1}{c}{ LDH } \\
\hline$+1.0 \pm 3.5$ & $+0.1 \pm 3.9$ & $-0.1 \pm 5.7$ \\
$+1.8 \pm 2.2$ & $-0.5 \pm 8.4$ & $+0.8 \pm 5.5$ \\
$-22.2^{*} \pm 6.4$ & $-19.6 \pm 7.9$ & $-6.4 \pm 3.5$ \\
$-42.5^{* * *} \pm 3.1$ & $-59.8^{* * *} \pm 4.2$ & $-23.9^{*} \pm 5.9$ \\
$-32.0^{* * *} \pm 3.6$ & $-59.6^{* * *} \pm 4.7$ & $-15.3^{*} \pm 3.8$ \\
$-15.1 \pm 5.7$ & $-37.9^{*} \pm 10.1$ & $-9.1 \pm 9.9$ \\
$-26.4 \pm 9.9$ & $-53.9^{*} \pm 11.1$ & $-8.8 \pm 9.8$ \\
$-3.7 \pm 8.7$ & $+6.6 \pm 9.2$ & $-1.7 \pm 7.8$ \\
$-5.1 \pm 12.3$ & $-2.3 \pm 14.7$ & $-18.8^{*} \pm 7.1$ \\
\hline
\end{tabular}

synthase; HOAD, $\beta$-hydroxyacyl CoA dehydrogenase; and LDH, lactate dehydrogenase. See

both denervated and deafferented groups suggest an important neural effect on the regulation of muscle mass.

JAWEED et al. (1987) reported that bilateral L5 neurectomy in rats did not cause a significant atrophy in soleus, even though 80 to $90 \%$ of soleus fibers are innervated by L5 spinal nerve. The possible mechanisms mentioned by them as the cause of non-significant decrease in muscle weight were 1) compensatory hypertrophy in non-denervated fibers and 2) increased innervation field by peripheral sprouting in non-denervated motoneurons. They compared the muscle weight between the neurectomized and normal control rats. But in the current study, the comparison was done between the experimental and the contralateral control sides since no significant difference was observed in the muscle weight of control side between each group. Furthermore, L5 neurectomy alone was not performed but significant atrophy in soleus was induced by L4 neurectomy, suggesting a contribution of $\mathrm{L} 4$ spinal nerve to soleus. The data may also suggest that plantaris might be mainly innervated by L5 nerve since no significant atrophy was induced in plantaris following L4 neurectomy but the weight was decreased more than $60 \%$ in response to the combination of L4 and L5 neurectomy.

The patterns of the changes in wet muscle weight and total protein in response to each treatment were similar. The data suggest that the atrophy was caused by the loss of protein by either increased protein degradation, decreased synthesis, or a combination of both. It was reported that denervation caused mainly an increased protein breakdown and a decreased synthesis (GolDBERG, 1969; GoldSPINK et al., 1983). The decrease in protein synthesis may be due to the decreased RNA (GolDSPINK et al., 1983), since $80-85 \%$ of muscle RNA is ribosomal (MILlWARD et al., 1976). It was also reported by HerBison et al. (1978) that decreased protein content after tenotomy, denervation, and limb casting was due to decrease in 
myofibrillar protein but not in sarcoplasmic protein. Greater decrease in mitochondrial than cytoplasmic enzyme activities found in the current study suggest a severe loss of mitochondrial protein following denervation.

Muscles are stretched passively and the load is increased when the synergistic muscle is tenotomized (GoldSPINK et al., 1983). Stretching (FrANKENY et al., 1983; Ashmore et al., 1984) and/or increased load (CRAWFORD, 1961; GoldBerg, 1967; Hamosh et al., 1967; SCHIAfFino and Hanzlikova, 1970; GoldSPINK et al., 1983; JAWEED et al., 1987) cause muscle hypertrophy. The activity of electromyogram recorded from rat soleus and plantaris during walking and standing was greater 3 days after the tenotomy of gastrocnemius relative to the pre-treatment level, suggesting a compensatory increase in the utilization of soleus and plantaris (OHIRA, 1988). Such elevation of neural and muscular activity (OHIRA, 1988) or tension production (VANDENBURGH, 1987) might be one of the factors for the induction of muscle hypertrophy.

Stretch-induced hypertrophy also can be induced in uninnervated myotubes and fibroblasts (VANDENBURGH and KAUFMAN, 1979, 1980). By contrast, stretching of the denervated, mature, frog sartorius muscles cultured for 5 days caused detrimental effects in our previous study-decrease in total protein, contractile properties, and enzyme activities - although muscles retained normal properties if they were cultured at approximately $93 \%$ of resting length in vivo (OHIRA et al., in press). This result may be due to the fact that the muscle lost both efferent and afferent nerve supplies and the possibility to readapt in response to stretching. Muscle weight, total protein, and enzyme activities were identical between 2 groups, with and without synergistic tenotomy, when the efferent and/or afferent fibers were cut in the current study. Compensatory hypertrophy was induced 2 weeks following the tenotomy of the gastrocnemius only when the neural supply was intact. GOLDSPINK et al. (1983) reported that, although compensatory hypertrophy was correlated with increases in both protein synthetic and degradative rates, the rate of increase was greater for synthesis than degradation.

HENRIKSSON et al. (1982) reported that 4-week denervation caused a significant decrease (approximately $45 \%$ ) in the activity of succinate dehydrogenase measured as a marker enzyme of tricarboxylic acid cycle in cat soleus but not in gastrocnemius. On the other hand, the activity of phosphofructokinase in the glycolytic pathway decreased more in gastrocnemius (approximately $72 \%$ ) than in soleus (approximately $23 \%$ ) in response to denervation. The activities of citrate synthase, $\beta$-hydroxyacyl CoA dehydrogenase, and lactate dehydrogenase decreased following denervation at L4 and L5 in the current study. The decrease in mitochondrial enzymes was approximately $40-60 \%$, and $24-27 \%$ for lactate dehydrogenase. These results roughly agree with the data obtained from cat soleus by HENRIKsson $e t$ al. (1982). Greater decrease in oxidative enzyme after denervation was also reported elsewhere (NEMETH, 1982; KHASKIYE et al., 1986).

All of the enzyme activities expressed relative to muscle weight tended to decrease in both plantaris and soleus muscles when they were overloaded fun- 
ctionally by tenotomy of gastrocnemius in the current investigation. Such tendency may be influenced by the increased muscle weight with probably no significant change in the absolute enzyme content. But in soleus muscle, decrease in citrate synthase activity (approximately $22 \%$ ) was statistically significant and that in $\beta$ hydroxyacyl CoA dehydrogenase (approximately $20 \%, p>0.05$ ) also tended to be greater than in lactate dehydrogenase (approximately $6 \%, p>0.05$ ). But it is unclear whether the decrease in mitochondrial enzyme activities of soleus was caused either by increased loss of protein, or inhibition of the activity, or dilution due to the increased muscle mass.

In conclusion, effects of denervation and deafferentation on muscle mass, protein content, and enzyme activity were studied in rats. Effects of them on induction of compensatory hypertrophy and metabolic characteristics in soleus and plantaris muscles were also investigated when the synergistic gastrocnemius was tenotomized. Muscle atrophy was induced due to decreased protein content following both denervation and deafferentation. The degree of atrophy was greater after denervation than deafferentation. Denervation also caused a decrease in both mitochondrial and cytoplasmic enzyme activities. Compensatory hypertrophy was induced only when the neural supply was intact. No compensatory effects were observed in muscle mass and enzyme activity in both denervated and deafferentated muscles. The data suggest that efferent neural information(s) has an important effect on the regulation of both morphology and function of skeletal muscles. Denervation had a greater effect on mitochondrial than on cytoplasmic enzymes. It is also suggested that afferent information(s) plays a significant role for the regulation of muscle mass. It is further clear that both efferent and afferent nerve supplies have to be intact for the induction of compensatory hypertrophy in response to tenotomy of synergistic muscle.

The author is grateful to Drs. Y. Fukami and P. M. Nemeth, Washington University School of Medicine, St. Louis, Missouri, U.S.A., for their kind instruction on the surgical technique.

A part of this report was presented at the 8th Annual Meeting, IUPS Commission on Gravitational Physiology, Tokyo, Japan, 1986.

\section{REFERENCES}

Ashmore, C. R., Lee, Y. B., Summers, P., and HitchCock, L. (1984) Stretch-induced growth in chicken wing muscles: nerve-muscle interaction in muscular dystrophy. $\mathrm{Am}$. J. Physiol., 246 (Cell Physiol., 15): C378-C384.

Bass, A., BrdiczKa, D., Eyer, P., Hoffer, S., and Pette, D. (1969) Metabolic differentiation of distinct muscle types at the level of enzymatic organization. Eur. J. Biochem., 10: $198-206$.

Воотн, F. W. (1977) Time course of muscular atrophy during immobilization of hindlimb in rats. J. Appl. Physiol.: Respir. Environ. Exerc. Physiol., 43: 656-661.

Воотн, F. W. (1982) Effect of limb immobilization on skeletal muscle. J. Appl. Physiol.: Respir. Environ. Exerc. Physiol., 52: 1113-1118. 
Coyle, E. F., Martin, W. H., III, Sinacore, D. R., Joyner, M. J., Hagberg, J. M., and Holloszy, J. O. (1984) Time course of loss of adaptations after stopping prolonged intense endurance training. J. Appl. Physiol.: Respir. Environ. Exerc. Physiol., 57: $1857-1864$.

CRAWFORD, G. N. C. (1961) Experimentally induced hypertrophy of growing voluntary muscle. Proc. R. Soc. Lond. (B), 154: 130-138.

Davis, H. L. and Heinicke, E. A. (1984) Prevention of denervation atrophy in muscle: mammalian neurotrophic factor is not transferrin. Brain Res., 309: 293-298.

FLYNN, D. E. and MAX, S. R. (1985) Effects of suspension hypokinesia/hypodynamia on rat skeletal muscle. Aviat. Space Environ. Med., 56: 1065-1069.

Frankeny, J. R., Holly, R. G., and Ashmore, C. R. (1983) Effects of graded duration of stretch on normal and dystrophic skeletal muscle. Muscle Nerve, 6: 269-277.

GoldberG, A. L. (1967) Work-induced growth of skeletal muscle in normal and hypophysectomized rats. Am. J. Physiol., 213: 1193-1198.

GoldBerG, A. L. (1969) Protein turnover in skeletal muscle. II. Effects of denervation and cortisone on protein catabolism in skeletal muscle. J. Biol. Chem., 244: 3223-3229.

Goldspink, D. F., Garlick, P. J., and McNurlan, M. A. (1983) Protein turnover measured in vivo and in vitro in muscles undergoing compensatory growth and subsequent denervation atrophy. Biochem. J., 210: 89-98.

Hamosh, M., Lesch, M., Baron, J., and Kaufman, S. (1967) Enhanced protein synthesis in a cell-free system from hypertrophied skeletal muscle. Science, 157: 935-937.

Henriksson, J., Galbo, H., and Blomstrand, E. (1982) Role of the motor nerve in activity-induced enzymatic adaptation in skeletal muscle. Am. J. Physiol., 242 (Cell Physiol., 11): C272-C277.

Herbison, G. J., JAWEed, M. M., and Ditunno, J. F. (1978) Muscle fiber atrophy after cast immobilization in the rat. Arch. Phys. Med. Rehabil., 59: 301-305.

Holloszy, J. O. (1967) Biochemical adaptations in muscle. Effects of exercise on mitochondrial oxygen uptake and respiratory enzyme activity in skeletal muscle. J. Biol. Chem., 242: $2278-2282$.

Ilyina-Kakueva, E. I., Portugalov, V. V., and Krivenkova, N. P. (1976) Space flight effects on the skeletal muscles of rats. Aviat. Space Environ. Med., 47: 700-703.

JAweEd, M. M., Herbison, G. J., and Ditunno, J. F., Jr. (1987) Overwork-induced axonal hypertrophy in the soleus nerve of the rat. Arch. Phys. Med. Rehabil., 68: 706-709.

KhaskiYe, A., Renaud, D., and LeDouarin, G. H. (1986) Effects of denervation and direct electrical stimulation upon the post-hatching differentiation of posterior latissimus dorsi muscle in chicken. Cell Differ., 18: 27-35.

LeOnard, J. I., Leach, C. S., and Rambaut, P. C. (1983) Quantitation of tissue loss during prolonged space flight. Am. J. Clin. Nutr., 38: 667-679.

Lowry, O. H., Rosebrough, N. J., Farr, A. L., and Randall, R. J. (1951) Protein measurement with the Folin phenol reagent. J. Biol. Chem., 193: 265-275.

Markelonis, G. J. and OH, T. H. (1978) A protein fraction from peripheral nerve having neurotrophic effects on skeletal muscle cells in culture. Exp. Neurol., 58: 285-295.

Millward, D. J., Garlick, P. J., Nanyelugo, D. O., and Waterlow, J. C. (1976) The relative importance of muscle protein synthesis and breakdown in the regulation of muscle mass. Biochem. J., 156: 185-188.

Musacchia, X. J., Deavers, D. R., Meininger, G. A., and Davis, T. P. (1980) A model for hypokinesia: effects on muscle atrophy in the rat. J. Appl. Physiol: Respir. Environ. Exerc. Physiol., 48: 479-486. 
Nemeth, P. M. (1982) Electrical stimulation of denervated muscle prevents decreases in oxidative enzymes. Muscle Nerve, 5: 134-139.

Nemeth, P. M., MeYer, D., and KARK, R.A.P. (1980) Effects of denervation and simple disuse on rates of oxidation and on activities of four mitochondrial enzymes in type $I$ muscle. J. Neurochem., 35: 1351-1360.

OH, T. H., Markelonis, G. J., Reier, P. J., and Zalewski, A. A. (1980) Persistence in degenerating sciatic nerve of substances having a trophic influence upon cultured muscle. Exp. Neurol., 67: 646-654.

OHIRA, Y. (1988) Neural effects on induction of compensatory hypertrophy. In: 65 th Annual Meeting Physiological Society Japan, p. 271.

Ohira, Y., Ohira, M., Chen, M., and Holloszy, J. O.: Organ culture of frog muscle: Maintenance of mass, enzyme levels and contractile force. J. Appl. Physiol., in press.

Ohira, Y., Tabata, I., Shibayama, H., and Ohira, M. (1987) Effects of head-down tilt suspension on mass and enzymatic profiles in various types of muscles. In: Biological Sciences in Space 1986, ed. by Watanabe, S., Mitarai, G., and Mori, S., MYU Research, Tokyo, pp. 129-134.

Pesce, A., McKay, R. H., Stolzenbach, F., Cahn, R. D., and Kaplan, N. O. (1964) Comparative enzymology of LDH. J. Biol. Chem., 239: 1753-1761.

Schiaffino, S. and Hanzlikova, V. (1970) On the mechanism of compensatory hypertrophy in skeletal muscles. Experientia, 26: 152-153.

Srere, P. A. (1969) Citrate synthase. Methods Enzymol., 13: 3-5.

VANDENBURGH, H. H. (1987) Motion into mass: how does tension stimulate muscle growth? Med. Sci. Sports Exerc. (Suppl.), 19: S142-S149.

VANDENBuRGH, H. and KaUfman, S. (1979) In vitro model for stretch-induced hypertrophy of skeletal muscle. Science, 203: 265-268.

VANDENBurgh, H. H. and Kaufman, S. (1980) In vitro skeletal muscle hypertrophy and $\mathrm{Na}$ pump activity. In: Plasticity of Muscle, ed. by PetTe, D., Walter de Gruyter and Co., New York, pp. 493-506. 